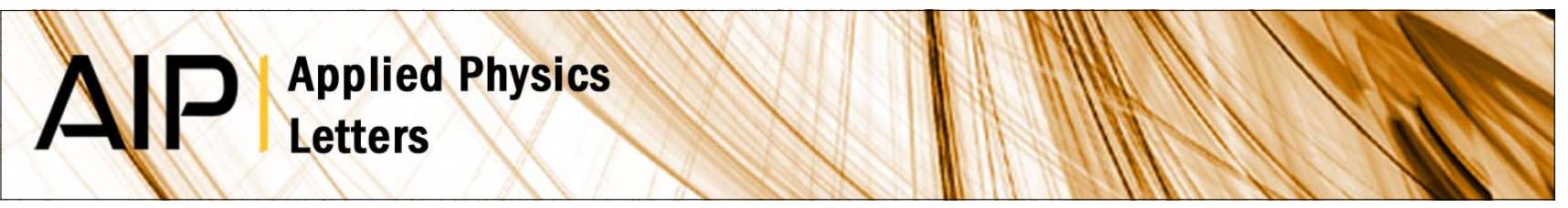

\title{
Efficient hybrid organic-inorganic light emitting diodes with self-assembled dipole molecule deposited metal oxides
}

Ji Sun Park, Bo Ram Lee, Ju Min Lee, Ji-Seon Kim, Sang Ouk Kim et al.

Citation: Appl. Phys. Lett. 96, 243306 (2010); doi: 10.1063/1.3453759

View online: http://dx.doi.org/10.1063/1.3453759

View Table of Contents: http://apl.aip.org/resource/1/APPLAB/v96/i24

Published by the AIP Publishing LLC.

Additional information on Appl. Phys. Lett.

Journal Homepage: http://apl.aip.org/

Journal Information: http://apl.aip.org/about/about_the_journal

Top downloads: http://apl.aip.org/features/most_downloaded

Information for Authors: http://apl.aip.org/authors

\section{ADVERTISEMENT}

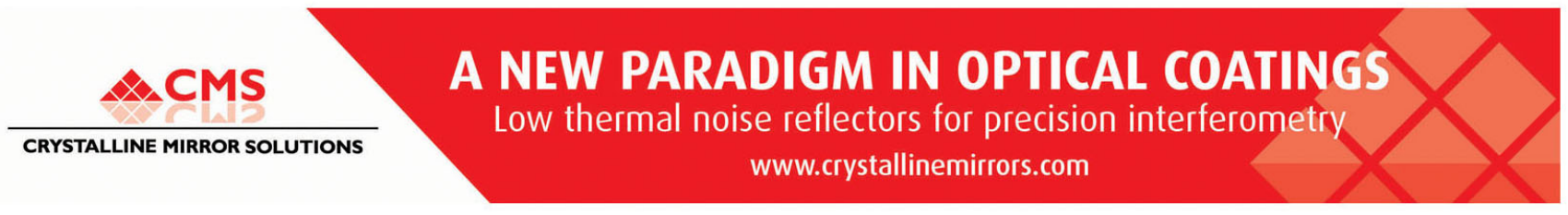




\title{
Efficient hybrid organic-inorganic light emitting diodes with self-assembled dipole molecule deposited metal oxides
}

\author{
Ji Sun Park, ${ }^{1}$ Bo Ram Lee, ${ }^{2}$ Ju Min Lee, ${ }^{1}$ Ji-Seon Kim, ${ }^{3}$ Sang Ouk Kim, ${ }^{1, a)}$ and \\ Myoung Hoon Song ${ }^{2, b)}$ \\ ${ }^{1}$ Department of Materials Science and Engineering, KAIST, Daejeon 305-701, Republic of Korea \\ ${ }^{2}$ School of Mechanical and Advanced Materials Engineering, Ulsan National Institute of Science \\ and Technology (UNIST), Banyeon-ri 100, Ulsan 689-805, Republic of Korea \\ ${ }^{3}$ Department of Physics and Centre for Plastic Electronics, Imperial College London, Prince Consort Road, \\ London SW7 2AZ, United Kingdom
}

(Received 24 March 2010; accepted 24 May 2010; published online 16 June 2010)

\begin{abstract}
We investigate the effect of self-assembled dipole molecules (SADMs) on $\mathrm{ZnO}$ surface in hybrid organic-inorganic polymeric light-emitting diodes (HyPLEDs). Despite the SADM being extremely thin, the magnitude and orientation of SADM dipole moment effectively influenced the work function of the $\mathrm{ZnO}$. As a consequence, the charge injection barrier between the conduction band of the $\mathrm{ZnO}$ and the lowest unoccupied molecular orbital of poly $\left(9,9^{\prime}\right.$-dioctylfluorene)co-benzothiadiazole could be efficiently controlled resulting that electron injection efficiency is remarkably enhanced. The HyPLEDs modified with a negative dipolar SADM exhibited enhanced device performances, which correspond to approximately a fourfold compared to those of unmodified HyPLEDs. (C) 2010 American Institute of Physics. [doi:10.1063/1.3453759]
\end{abstract}

The challenging demand for ultrathin, mechanically flexible displays has stimulated research attention on polymer light-emitting diodes (PLEDs). ${ }^{1}$ Among various device architectures, hybrid organic-inorganic polymeric lightemitting diodes (HyPLEDs) that utilize metal oxides as charge transporting and injection layers are promising candidates for low-cost, high-performance, and solutionprocessible flexible displays. HyPLEDs exhibit high luminance, low turn-on voltages, and exceptional air stability, largely owing to the attractive properties of metal oxide layers, such as high electrical conductivity, tunable refractive index, excellent air stability, and high optical transparency. ${ }^{2-7}$ Nevertheless, considerable room for the enhancement of the device performances of HyPLEDs still remains. As an example, n-type metal oxide such as $\mathrm{ZnO}$ is frequently used as an electron injection layer for a poly $\left(9,9^{\prime}\right.$ dioctylfluorene)-co-benzothiadiazole (F8BT) emissive layer. ${ }^{3,7}$ However, injection barrier between the conduction band of the $\mathrm{ZnO}(\sim 4.0 \mathrm{eV})$ (Ref. 8) and the lowest unoccupied molecular orbital (LUMO) of the F8BT $(\sim 3.0-3.5 \mathrm{eV})$ (Ref. 9) hinders efficient electron injection.

Recent work on HyPLEDs has demonstrated that $\mathrm{MoO}_{3}$ provides an unprecedented Ohmic contact to the high ionization potential of F8BT, which is a widely used, air-stable, and highly efficient green-light-emitting polymer. Owing to the idealized electric contact, an extremely high injection current density of holes can be generated. ${ }^{6,10}$ Consequently, electron and hole injection from each electrode is seriously unbalanced such that the recombination probability of electrons and holes is significantly deteriorated. For optimized device performance of HyPLEDs employing a $\mathrm{MoO}_{3}$ hole injection layer, enhanced electron injection at the counter electrode is crucial to balance the charge injection. To date, several approaches have been exploited to promote electron

\footnotetext{
${ }^{a)}$ Electronic mail: sangouk.kim @kaist.ac.kr.

${ }^{b)}$ Electronic mail: mhsong@unist.ac.kr.
}

injection by interfacial modification between the electron injection layer and emissive polymer layers. Electrodes with cesium carbonate $\left(\mathrm{Cs}_{2} \mathrm{CO}_{3}\right),{ }^{2,4}$ metal fluoride, ${ }^{11}$ conjugated polyelectrolytes, ${ }^{12}$ ionic polymers, ${ }^{13}$ and radiative surface treatment of electrodes ${ }^{14}$ have been reported to improve electron injection so far.

Here we present a straightforward strategy to remarkably enhance the electron injection efficiency of HyPLEDs by surface modification of n-type metal oxide using selfassembled dipole molecules (SADMs).

The complete device architecture of HyPLEDs with a single F8BT layer and the chemical structures of carboxylic acid based SADMs employed in this work are presented in Fig. 1. The HyPLEDs were prepared by the sequential deposition of fluorine doped tin oxide, $\mathrm{ZnO}$, SADM, F8BT, $\mathrm{MoO}_{3}$, and Au layers [Fig. 1(a)]. An $80 \mathrm{~nm}$ thick n-type $\mathrm{ZnO}$ layer was prepared by spray pyrolysis deposition from $80 \mathrm{mg} \mathrm{mL}^{-1}$ zinc acetate dihydrate/methanol precursor solutions. The surface of the $\mathrm{ZnO}$ layer was modified with a few nanometer thick SADM layer by spin-coating from $7 \mathrm{mM}$

(a)
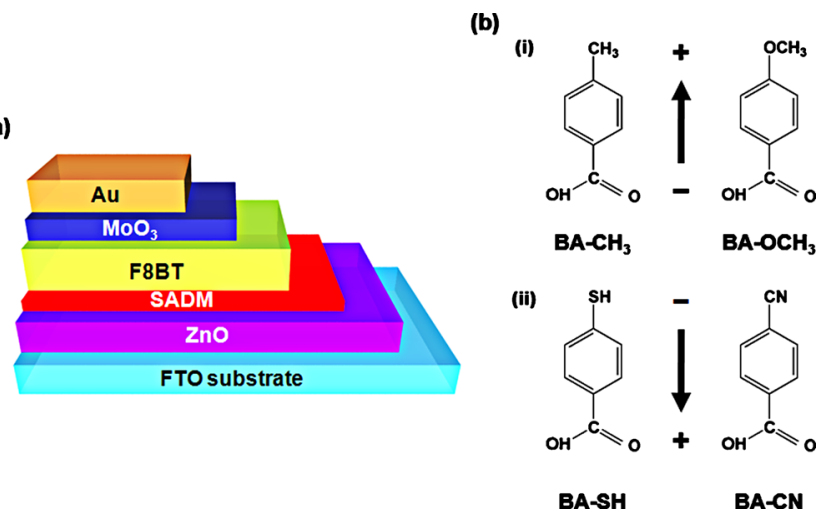

FIG. 1. (Color online) (a) Device architecture of single F8BT layer HyPLEDs with SADMs on a $\mathrm{ZnO}$ surface. (b) Chemical structures of carboxylic acid based SADMs: (i) negative dipole molecules: $\mathrm{BA}-\mathrm{CH}_{3}$, and $\mathrm{BA}-\mathrm{OCH}_{3}$, (ii) positive dipole molecules: $\mathrm{BA}-\mathrm{SH}$ and $\mathrm{BA}-\mathrm{CN}$. 
ethanol solutions. The carboxylic acid based SADMs consisting of (i) negative dipoles containing an electrondonating group and (ii) positive dipoles containing an electron-withdrawing group are well-known interfacial modifiers for hydroxyl $(-\mathrm{OH})$ terminated metal oxides [Fig. 1(b)]. ${ }^{15,16}$ A uniform SADM layer was readily formed on the $\mathrm{ZnO}$ surface through the covalent bonding between the carboxyl group $(-\mathrm{COOH})$ of the SADM and the hydroxyl group $(-\mathrm{OH})$ of the $\mathrm{ZnO}$. The formation of an SADM layer was confirmed by contact angle measurement. A $100 \mathrm{~nm}$ thick F8BT emissive layer was spin cast from $20 \mathrm{mg} \mathrm{mL}^{-1}$ p-xylene solutions onto the SADM-modified $\mathrm{ZnO}$ surface, and then thermal annealing was performed at $155^{\circ} \mathrm{C}$ for $1 \mathrm{~h}$ under a nitrogen atmosphere ${ }^{17} \mathrm{~A} 10 \mathrm{~nm}$ thick p-type $\mathrm{MoO}_{3}$ layer and a $60 \mathrm{~nm}$ thick Au layer were subsequently evaporated on the F8BT layer to complete the device fabrication.

The presence of adequate molecular dipoles at the interface between $\mathrm{ZnO}$ and polymer emissive layer plays a crucial role in enhancing the charge injection within devices. The carboxylic acid based SADMs employed in this study have two types of dipole moments $(\mu)$. One is pointing away from the $\mathrm{ZnO}$ surface $\left(\mathrm{BA}-\mathrm{CH}_{3}\right.$ and $\left.\mathrm{BA}-\mathrm{OCH}_{3}\right)$ and another is pointing toward the $\mathrm{ZnO}$ surface (BA-SH and $\mathrm{BA}-\mathrm{CN}$ ), as described in Fig. 1(b). In accordance with the dipole moments of SADMs, the expected variation in the $\mathrm{ZnO}$ work function $(\Delta \Phi)$ is given as follows: ${ }^{18}$

$$
\Delta \Phi=e N\left(\frac{\mu_{n}}{\varepsilon_{\mathrm{SADM}} \varepsilon_{0}}\right),
$$

where $N$ is the surface density of the molecules, $\mu_{n}$ is the molecular dipole moment normal to the surface, $\varepsilon_{\mathrm{SADM}}$ is the dielectric constant of the SADM, and $\varepsilon_{0}$ is the permittivity of free space. According to the previously reported literature values, the dielectric constant of aromatic molecules is assumed to be $\varepsilon_{\mathrm{SADM}}=5.3$. The sign of $\mu_{n}$ depends on the direction of the dipoles. The negative dipole $\left(\mu_{n}<0\right)$ indicates that the dipole moment points away from $\mathrm{ZnO}$ surface, whereas the positive dipole $\left(\mu_{n}>0\right)$ corresponds to the dipole moment points toward the $\mathrm{ZnO}$ surface. It is worth noting that the surface coverage, $N$, is also an important parameter in determining the magnitude of $\Delta \Phi$.

Figures 2(a)-2(c), schematically illustrate the energy band diagrams for flat band conditions of HyPLEDs without or with SADM modification. ${ }^{15,16}$ A dipole moment pointed away from the $\mathrm{ZnO}$ [Fig. 2(b)] would effectively shift the band edge of the $\mathrm{ZnO}$ closer to the vacuum level of the F8BT. Accordingly, the work function of $\mathrm{ZnO}$ and the energy barrier to electron injection would decrease from those without SADM interface modification [Fig. 2(a)]. In contrast, a dipole moment pointing toward the $\mathrm{ZnO}$ surface [Fig. 2(c)] would conversely shift the band edge of the $\mathrm{ZnO}$ away from the local vacuum level of the F8BT and increase the work function and the energy barrier for electron injection.

In order to clarify the effect of the molecular dipoles on the $\mathrm{ZnO}$ work function, ultraviolet photoemission spectroscopy (UPS) measurements were performed. Figure 2(d) shows the variation in the experimentally measured work functions of the $\mathrm{ZnO}\left(\Phi_{\mathrm{ZnO}}\right)$ as a function of the SADM dipole moments $\left(\mu_{\mathrm{SADM}}\right)$. The $\mu_{\mathrm{SADM}}$ values were confirmed by calculation using CHEM3D ULTRA software. As expected, negative dipoles effectively lowered the work function of the
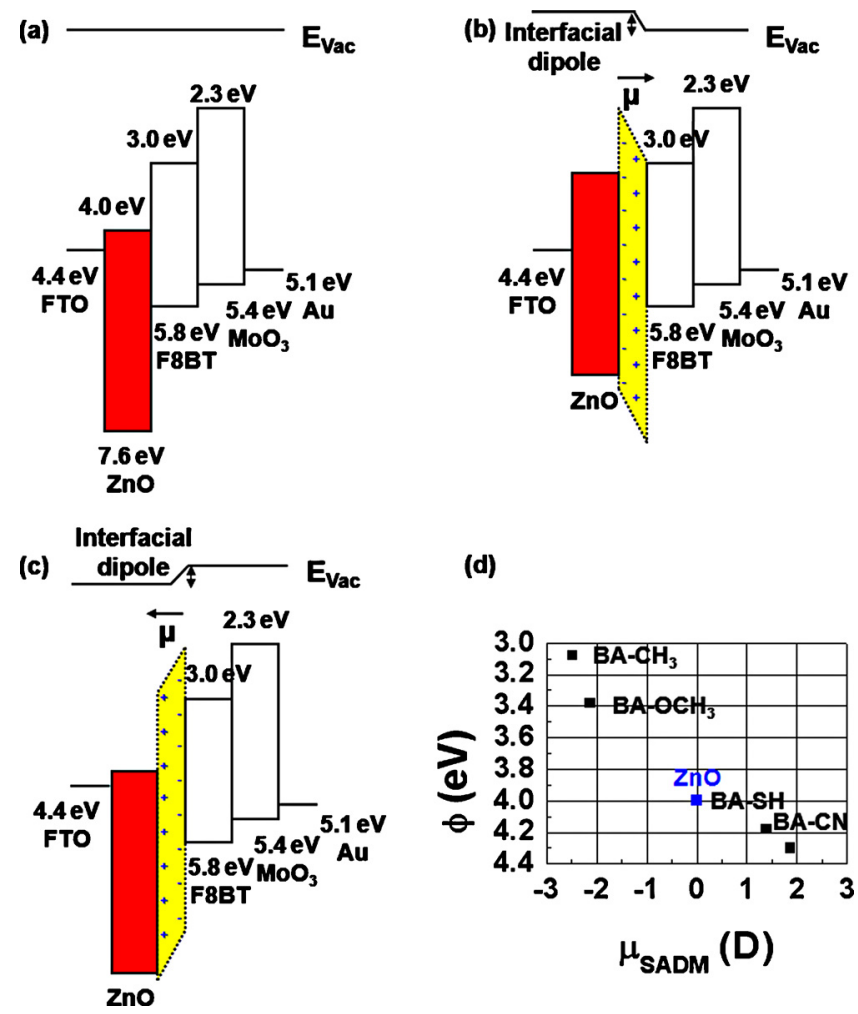

FIG. 2. (Color online) Schematic energy diagrams for flat band conditions of HyPLEDs with (a) unmodified $\mathrm{ZnO}$, (b) negative, and (c) positive SADM modified $\mathrm{ZnO}$. (d) Experimentally measured work functions of $\mathrm{ZnO}$ as a function of the $\mu_{\mathrm{SADM}}$ using UPS.

ZnO: $3.08 \mathrm{eV}$ for $\mathrm{BA}-\mathrm{CH}_{3}$-modified $\mathrm{ZnO}$, and $3.38 \mathrm{eV}$ for BA- $\mathrm{OCH}_{3}$-modified $\mathrm{ZnO}$, while $4.0 \mathrm{eV}$ for unmodified $\mathrm{ZnO}$. Positive dipoles raised the work function: $4.18 \mathrm{eV}$ for BA-SH-modified $\mathrm{ZnO}$ and $4.3 \mathrm{eV}$ for BA-CN-modified $\mathrm{ZnO}$.

The device performances of HyPLEDs with SADMmodified $\mathrm{ZnO}$ are presented in Fig. 3. The device perfor- (a)

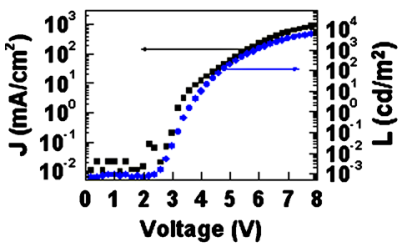

(c)

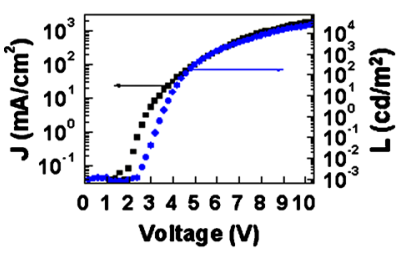

(e)

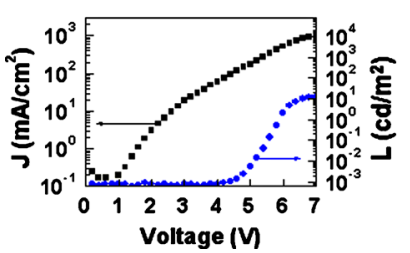

(b)

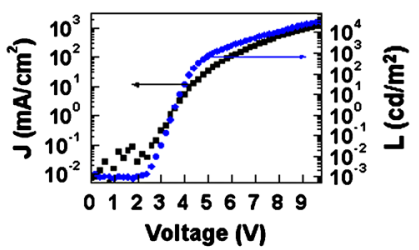

(d)

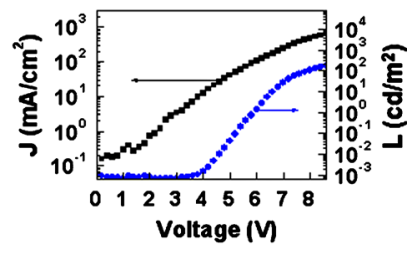

(f)

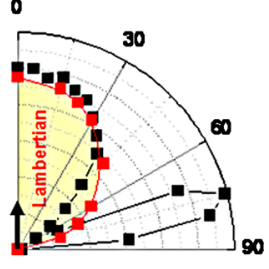

FIG. 3. (Color online) J-V-L characteristics for SADM-modified ZnO layer in HyPLEDs. 
TABLE I. Detailed device characteristics of HyPLEDs without or with SADM modification of $\mathrm{ZnO}$.

\begin{tabular}{|c|c|c|c|}
\hline $\begin{array}{c}\text { Device } \\
\text { configuration }\end{array}$ & $\begin{array}{l}\text { Maximum } \\
\text { luminance } \\
\left(\mathrm{cd} / \mathrm{m}^{2}\right) \\
\text { (at voltage) }\end{array}$ & $\begin{array}{c}\text { Maximum } \\
\text { luminous efficiency } \\
(\mathrm{cd} / \mathrm{A}) \\
\text { (at voltage) }\end{array}$ & $\begin{array}{c}\text { Turn on voltage } \\
\text { (V) }\end{array}$ \\
\hline $\mathrm{ZnO} / \mathrm{F} 8 \mathrm{BT}$ & $11000(9.4 \mathrm{~V})$ & $0.7(8.0 \mathrm{~V})$ & 2.4 \\
\hline $\mathrm{ZnO} / \mathrm{BA}-\mathrm{CH}_{3}$ & $38000(9.8 \mathrm{~V})$ & $2.8(9.6 \mathrm{~V})$ & 2.2 \\
\hline $\mathrm{ZnO} / \mathrm{BA}-\mathrm{OCH}_{3}$ & $38200(10.4 \mathrm{~V})$ & $2.1(10.0 \mathrm{~V})$ & 2.4 \\
\hline $\mathrm{ZnO} / \mathrm{BA}-\mathrm{SH}$ & $200(8.8 \mathrm{~V})$ & $0.01(8.6 \mathrm{~V})$ & 4.0 \\
\hline $\mathrm{ZnO} / \mathrm{BA}-\mathrm{CN}$ & $15(7.6 \mathrm{~V})$ & $0.001(6.8 \mathrm{~V})$ & 4.6 \\
\hline
\end{tabular}

mances were evaluated by the current density and luminance versus applied voltage ( $\mathrm{J}-\mathrm{V}-\mathrm{L})$ measurements in atmospheric conditions without further encapsulation. Figures 3(a)-3(e) show the J-V-L characteristics of the devices employing an SADM-modified $\mathrm{ZnO}$ layer. We note that all the devices exhibited the original green emission of the F8BT, regardless of the SADM interfacial modification and applied voltages. In comparison to the devices without interfacial modification [Fig. 3(a)], those modified with negative dipole SADM, such as $\mathrm{BA}-\mathrm{CH}_{3}$ [Fig. 3(b)] and $\mathrm{BA}-\mathrm{OCH}_{3}$ [Fig. 3(c)], demonstrated remarkably enhanced PLED performances. They demonstrated greatly enhanced luminance and luminous efficiency and low turn-on voltages. In contrast, the devices modified with positive dipole SADM, such as BA-SH [Fig. 3(d)] and BA-CN [Fig. 3(e)], showed significant deterioration of device performances. Table I summarizes the detailed device characteristics including luminance, luminous efficiency, and turn-on voltages. The devices modified with the negative dipole molecules of $\mathrm{BA}-\mathrm{CH}_{3}$ shows the best device performance with a luminance of $38000 \mathrm{~cd} / \mathrm{m}^{2}$ (at $9.8 \mathrm{~V}$ ), luminous efficiency of $2.8 \mathrm{~cd} / \mathrm{A}$ (at $9.6 \mathrm{~V}$ ), and turn-on voltage of $2.2 \mathrm{~V}$, which correspond to approximately a fourfold increase in desirable characteristics compared to unmodified devices. We note that all of the characteristics elucidated in Table I were corrected with the correction factor of 1.2. Since the metal oxide has a high refractive index $\left(\mathrm{n}_{\mathrm{r}-\mathrm{ZnO}}\right.$ $\approx 2$ ), optical wave-guiding and non-Lambertian edge emissions occurred in these HyPLEDs. These effects resulted in angle dependent electroluminescent emission that considerably deviated from the Lambertian emission patterns of conventional PLEDs [Fig. 3(f)]. In our measurement setup, a photodetector is located in the forward direction with the luminance output calculated assuming a Lambertian emission. Thus, the correction of luminance and luminous efficiency was required for the exact evaluation of device performances. For the measurement of angular dependence of luminescence, a reference $\mathrm{Si}$ photodetector was rotated to detect the luminance output as a function of external viewing angle. A correction factor of 1.2 was obtained by comparing the two integrated values of measured emission patterns. ${ }^{3}$

The influence of SADM interfacial modification upon electron injection was also confirmed by electron-only device performance as shown in Fig. S1(a) (see section 1 in Ref. 19). As observed in J-V-L and electron-only device characteristics, the negative dipoles acted as molecular electron-injection layers, which reduced the injection barrier for electrons and facilitated the electron transporting and injection within HyPLEDs.

In summary, we have demonstrated that straightforward surface modification using SADMs remarkably enhances the electron injection efficiency of a metal oxide and the corresponding device performance of HyPLEDs. Despite the SADM being extremely thin, the magnitude and orientation of SADM dipole moment effectively influenced the work function of the $\mathrm{ZnO}$ layer. As a consequence, the charge injection barrier between the $\mathrm{ZnO}$ conduction band and the F8BT LUMO could be efficiently controlled. Our approach is potentially useful for advanced optoelectronic devices, such as electrically pumped organic laser diodes with enhanced electron injection efficiency of minority carriers, recombination opportunity, and reduced excited state optical absorption associated with injected carriers.

The authors thank Cambridge Display Technology (CDT), Ltd., for supplying F8BT. This work was supported by the Mid-career Researcher Program (Grant No. 20090085470), the National Research Laboratory Program (Grant No. R0A-2008-000-20057-0), the World Class University (WCU) Program (Grant No. R32-2008-000-10051-0), Center for Inorganic Photovoltaic Materials (ERC) (Grant No. 2008-0062204), Research Foundation of Korea (Grant No. NRF-2009-C1AAA001-2009-0093020), and the 2009 Research Fund of UNIST (Ulsan National Institute of Science and Technology).

${ }^{1}$ R. H. Friend, R. W. Gymer, A. B. Holmes, J. H. Burroughes, R. N. Marks, C. Taliani, D. D. C. Bradley, D. A. Dos Santos, J. L. Brédas, M. Lögdlund, and W. R. Salaneck, Nature (London) 397, 121 (1999).

${ }^{2}$ K. Morii, T. Kawase, and S. Inoue, Appl. Phys. Lett. 92, 213304 (2008).

${ }^{3}$ D. Kabra, M. H. Song, B. Wenger, R. H. Friend, and H. J. Snaith, Adv. Mater. 20, 3447 (2008)

${ }^{4}$ H. J. Bolink, E. Coronado, J. Orozco, and M. Sessolo, Adv. Mater. 21, 79 (2009).

${ }^{5}$ N. Tokmoldin, N. Griffiths, D. D. C. Bradley, and S. A. Haque, Adv. Mater. 21, 3475 (2009).

${ }^{6}$ Y. Nakayama, K. Morii, Y. Suzuki, H. Machida, S. Kera, N. Ueno, H. Kitagawa, Y. Noguchi, and H. Ishii, Adv. Funct. Mater. 19, 3746 (2009). ${ }^{7}$ M. H. Song, D. Kabra, B. Wenger, R. H. Friend, and H. J. Snaith, Adv. Funct. Mater. 19, 2130 (2009).

${ }^{8}$ H. J. Bolink, E. Coronado, D. Repetto, and M. Sessolo, Appl. Phys. Lett. 91, 223501 (2007).

${ }^{9}$ L.-L. Chua, J. Zaumseil, J-.F. Chang, E. C.-W. Ou, P. K.-H. Ho, H. Sirringhaus, and R. H. Friend, Nature (London) 434, 194 (2005).

${ }^{10}$ M. Kröger, S. Hamwi, J. Meyer, T. Riedl, W. Kowalsky, and A. Kahn, Org. Electron. 10, 932 (2009).

${ }^{11}$ L. S. Hung, C. W. Tang, and M. G. Mason, Appl. Phys. Lett. 70, 152 (1997)

${ }^{12}$ F. Huang, L. Hou, H. Wu, X. Wang, H. Shen, W. Cao, W. Yang, and Y. Cao, J. Am. Chem. Soc. 126, 9845 (2004).

${ }^{13}$ T- W. Lee and O. O. Park, Adv. Mater. 13, 1274 (2001).

${ }^{14}$ M. G. Mason, L. S. Hung, C. W. Tang, S. T. Lee, K. W. Wong, and M. Wang, J. Appl. Phys. 86, 1688 (1999).

${ }^{15}$ C. Goh, S. R. Scully, and M. D. McGehee, J. Appl. Phys. 101, 114503 (2007)

${ }^{16}$ H- L. Yip, S. K. Hau, N. S. Baek, H. Ma, and A. K. -Y. Jen, Adv. Mater. 20, 2376 (2008).

${ }^{17}$ C. L. Donley, J. Zaumseil, J. W. Andreasen, M. M. Nielsen, H. Sirringhaus, R. H. Friend, and J-. S. Kim, J. Am. Chem. Soc. 127, 12890 (2005).

${ }^{18}$ S. Khodabakhsh, D. Poplavskyy, S. Heutz, J. Nelson, D. D. C. Bradley, H. Murata, and T. S. Jones, Adv. Funct. Mater. 14, 1205 (2004).

${ }^{19}$ See supplementary material at http://dx.doi.org/10.1063/1.3453759 for more information (Section S1). 